\title{
UNCEMENTED PRIMARY TOTAL HIP ARTHROPLASTY FOR OSTEONECROSIS OF HIP WITH SECONDARY OSTEOARTHRITIS IN YOUNG ADULTS
}

Chatla Srinivas $^{1}$, P. Satish ${ }^{2}$, G.V.S. Moorthy33, V. K. V. Prasad ${ }^{4}$, Vamshi $^{5}$, Raju$^{6}$, Bhasker $^{7}$

${ }_{1}^{1}$ Assistant Professor, Department of Orthopaedics, Osmania General Hospital/Osmania Medical College. ${ }^{2}$ Assistant Professor, Department of Orthopaedics, Osmania General Hospital/Osmania Medical College. 3 Professor and HOD, Department of Orthopaedics, Osmania General Hospital/Osmania Medical College. ${ }^{4}$ Associate Professor, Department of Orthopaedics, Osmania General Hospital/Osmania Medical College. 5 Post Graduate, Osmania General Hospital/Osmania Medical College.

${ }_{6}^{6}$ Post Graduate, Osmania General Hospital/Osmania Medical College.

7Post Graduate, Osmania General Hospital/Osmania Medical College.

\section{ABSTRACT}

\section{BACKGROUND}

Osteonecrosis of the femoral head is a progressive disease that generally affects patients in the third through fifth decade of life, if left untreated. Currently, 18\% of all Total Hip Arthroplasty performed in USA are done for Osteonecrosis.(1) The aetiology for the Osteonecrosis varies from idiopathic, alcohol intoxication, steroid abuse or due to childhood hip disorders and hip trauma. We have selected 40 patients suffering from advanced femoral head osteonecrosis with subchondral collapse leading to Osteoarthritis of hip in young adults, treated by uncemented primary total hip replacement. This study is aimed to suggest that uncemented total hip arthroplasty can be applied predictably to this younger, potentially more active patient population.

\section{MATERIAL AND METHODS}

We have done 54 uncemented primary hips in 40 cases with mean follow-up of 5.5 years. The average age of the patient at the time of surgery was 43 years. All the hips are clinically and radiologically examined both pre- and post-operatively. All the cases are operated through postero-lateral approach and have used the fully Hydroxyapatite coated femoral straight stem designed for press fit insertion and hemispherical HA-coated cup inserted with press fit and in few cases we used an HA-coated screw. The patients are under regular follow-up.

\section{RESULTS}

All the patients are reviewed at 6 weeks, 3 months, 6 months and yearly thereafter. The clinical and functional status was recorded using the Harris Hip Score and WOMAC Hip Score. The mean Harris score has improved from an average of 44 points to an average of 93 points postoperatively; $94 \%$ showed good-to-excellent results, $2 \%$ of cases had shortening, one case developed hip dislocation after two weeks due to unguarded physiotherapy.

\section{CONCLUSION}

The short-term results of cementless total hip arthroplasty in patients with Osteonecrosis of the femoral head were encouraging. We await further follow-up to see if these promising results hold true.

\section{KEYWORDS}

Osteonecrosis, Total Hip Arthroplasty.

HOW TO CITE THIS ARTICLE: Srinivas C, Satish P, Moorthy GVS, et al. Uncemented primary total hip arthroplasty for osteonecrosis of HIP with secondary osteoarthritis in young adults. J. Evolution Med. Dent. Sci. 2016;5(22):1156-1159, DOI: $10.14260 /$ jemds/2016/269

\section{INTRODUCTION}

Osteonecrosis of the femoral head is a progressive disease that generally affects patients in the third through fifth decade of life. If left untreated it leads to complete deterioration of the hip joint. The incidence is increasing by 20,000 cases every year in USA and it has been noted around $18 \%$ of total hip replacement done in US is due to Osteonecrosis of hip.(1) Avascular necrosis is a misnomer; it is now called as Osteonecrosis. The risk factors causing Osteonecrosis is long and includes trauma, corticosteroids use, alcohol abuse, smoking, haemoglobinopathies, coagulation disorders, myeloproliferative disorders, caisson's disease, HIV infection and pregnancy.

Financial or Other, Competing Interest: None.

Submission 01-01-2016, Peer Review 12-02-2016,

Acceptance 18-02-2016, Published 16-03-2016.

Corresponding Author:

Dr. Chatla Srinivas,

Flat 105, B-36, SKS Residency,

DD Colony, Hyderabad-13.

E-mail: sriortho68@gmail.com

DOI: $10.14260 /$ jemds/2016/269
In many cases a cause cannot be identified and these are designated as having Idiopathic Osteonecrosis. The most commonly used classification for osteonecrosis of the femoral head was developed by Ficat and Arlet and is based on radiographic changes; $95 \%$ of the patients with less than $30 \%$ osteonecrotic lesion in the femoral head are asymptomatic for more than 5 years; however, the symptoms start with lesion increasing by $50 \%$. The disease progresses with subchondral collapse leading eventually to osteoarthritis of the hip joint.

The treatment modalities have evolved over the period of few decades ranging from core decompression to the present Total hip replacement. Steinberg ME, et al.(2) has treated 300 cases of AVN hips ranging from Stage 1 to Stage IV for various aetiologies with core decompression and bone grafting. He has followed for 2-12 years and found core decompression with cancellous bone grafting is a safe and effective procedure for the treatment of early avascular necrosis of the femoral head. Shannon BD.(3) et al. and Gallinaro P.(4) have advocated the method of femoral osteotomy. Flexion intertrochanteric osteotomy aimed at 
rotating the intact posterior portion of the femoral head into the weight bearing portion of the acetabulum gives satisfying long-term results in young and highly motivated patients who have a diagnosis of Ficat Stage II or Stage III idiopathic avascular necrosis. Cabanela ME.(5) et al., Lee SB.(6) et al. did a prospective comparative study of Bipolar hemiarthroplasty and Total Hip Arthroplasty using the same cementless femoral components for advanced Osteonecrosis of the hips.

Because of the incidence of gluteal and groin pain and migration in patients treated with Bipolar prosthesis, Total hip replacement is considered as better procedure for patients with Ficat Stage III Osteonecrosis of the femoral head. Lons A.(7) et al., Marshall D.(8) et al. have found in a selected population of young and/or active patients, the short-term results of hip resurfacing are excellent. At the postoperative 4-year follow-up the rate of complications (In particular the absence of dislocations) was less than that for THA in young and/or active patients. But long-term results are not successful.

Today, Total Hip Arthroplasty is perhaps the most commonly performed and successful surgery for advanced Osteonecrosis of the hip. However, clinical outcomes are inferior to those of total hip arthroplasty that is performed for osteoarthritis. Cementless prostheses with an improved design may afford increased longevity relative to cemented counterparts. Despite recent improvements in prosthetic replacement, replacement arthroplasty precludes further participation in impact activities (e.g., running, jogging), because these activities greatly decrease implant longevity.

\section{MATERIALS AND METHODS}

We have selected 40 cases suffering from Osteonecrosis of head of the femur staged Ficat and Arlet III and IV with secondary osteoarthritis of hip. The average age of the patient at the time of surgery is 43 years and considered as young if the age is below 50 years. Totally 54 uncemented hips are done, of which 14 are bilateral; 28 cases are males and 12 cases are females. In most of the cases the aetiology is Idiopathic, 6 cases due to alcoholic, 4 cases due to childhood hip disorders and 4 cases are due to hip trauma. All the patients are clinically examined and assessed functionally. Preoperative serology, biochemical evaluations are done to ensure proper fitness of the patient for surgery. X-rays of the hips, pelvis and spine are taken to measure the deformities, bone quality, various angles and finally sizing of the cup and stem.

All the hips are approached through the standard posterior-lateral incision. Hemi-spherical Hydroxyapatite (HA) coated press-fit acetabular cups with High Density Polyethylene (HDPE) liners are used for acetabulum. And for femur we have used fully HA coated, standard straight stem designed for press fit insertion. Postoperatively, patient's legs are kept apart with abduction pillow for two days and started with hip and knee isometric exercises. After four days, patient is advised for protected walking with hip and knee ROM exercises. Patients are advised for regular follow-up at 6 weeks, 12 and 24 weeks, thereafter for every 3 months. Postoperatively, patient is assessed for pain, movement and functional outcome based on Harris Hip score.(9) and WOMAC Hip Scoring.(10) We have followed up the patients for an average period of 5.5 years.

\begin{tabular}{|c|c|}
\hline Harris Hip Score & Points \\
\hline Criteria & 44 \\
Pain & 47 \\
Range of motion & 5 \\
Absence of deformity & 4 \\
\hline
\end{tabular}

\section{WOMAC Scores}

\begin{tabular}{|c|c|c|c|}
\hline Pain & Stiffness & Function & Total Scores \\
\hline $15(5-20)$ & $6(3-8)$ & $56(26-68)$ & $80(37-100)$ \\
\hline
\end{tabular}

\section{RESULTS}

Totally, 54 uncemented hip arthroplasty were done during the period 2008 to 2012 at Osmania General Hospital/Osmania Medical College, Hyderabad. In 26 cases unilateral uncemented hip arthroplasty was done, whereas bilateral hip arthroplasty was done in 14 patients. All the patients are followed up for a mean period of 5.5 years; 94.44\% (51 hips) showed good-to-excellent results; 5.55\% (3 hips) had fairer outcome, like one case had shortening on the operated side by about $1.5 \mathrm{~cm}$ which was covered by heel raise, another case developed dislocation of the hip postoperatively due to unguarded physiotherapy. One patient developed delayed infection of the operated hip, which was treated by debridement and intravenous antibiotics.

Clinical rating was according to the Harris Hip Score. The mean Harris Hip Score improved from 43 points to 87 points (Of a possible 100 points) at the most recent follow-up. The WOMAC score for osteoarthritis hip was used to assess the functional results, the WOMAC score 80 (Range: 37-100). Radiological assessment showed all stems have well integrated at recent follow up and there were no signs of loosening. There was one case of acetabular cup revision due to aseptic loosening, accounting to overall prosthesis survivorship of $97.5 \%$.

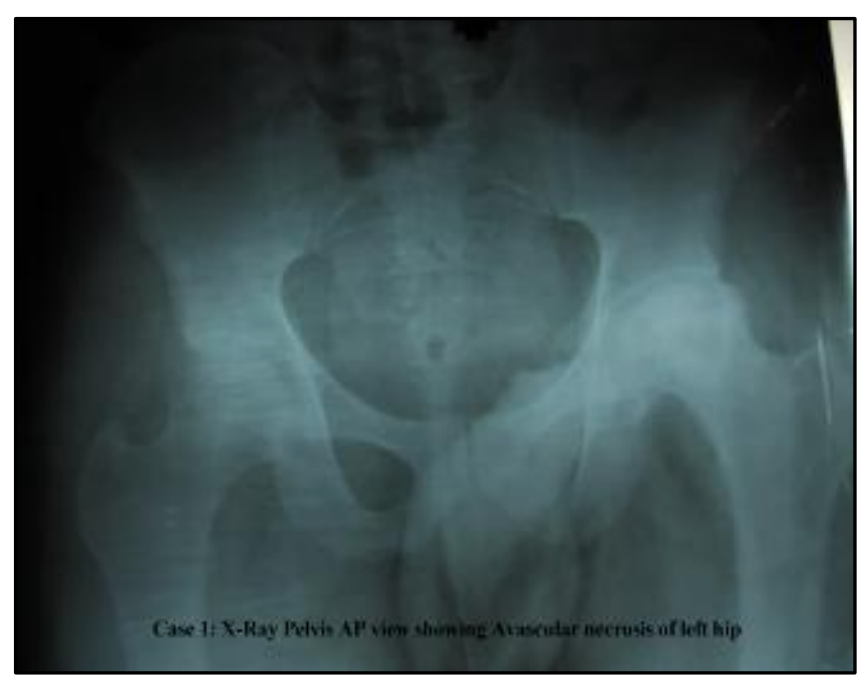

Case. 1: X-Ray Pelvis AP view showing Avascular Necrosis of left HIP 


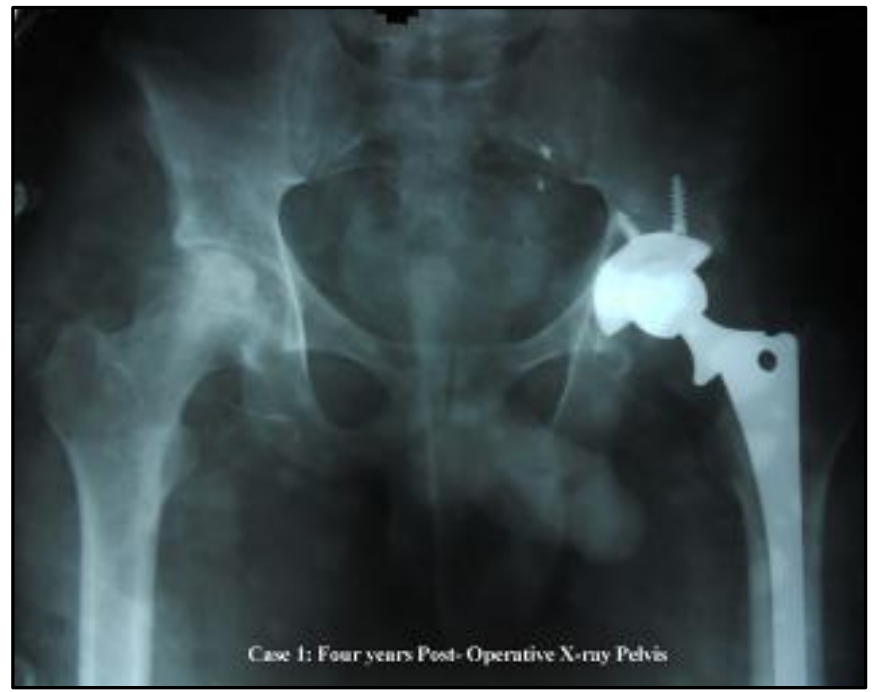

Case 1: Four Year Post-Operative X-Ray Pelvis

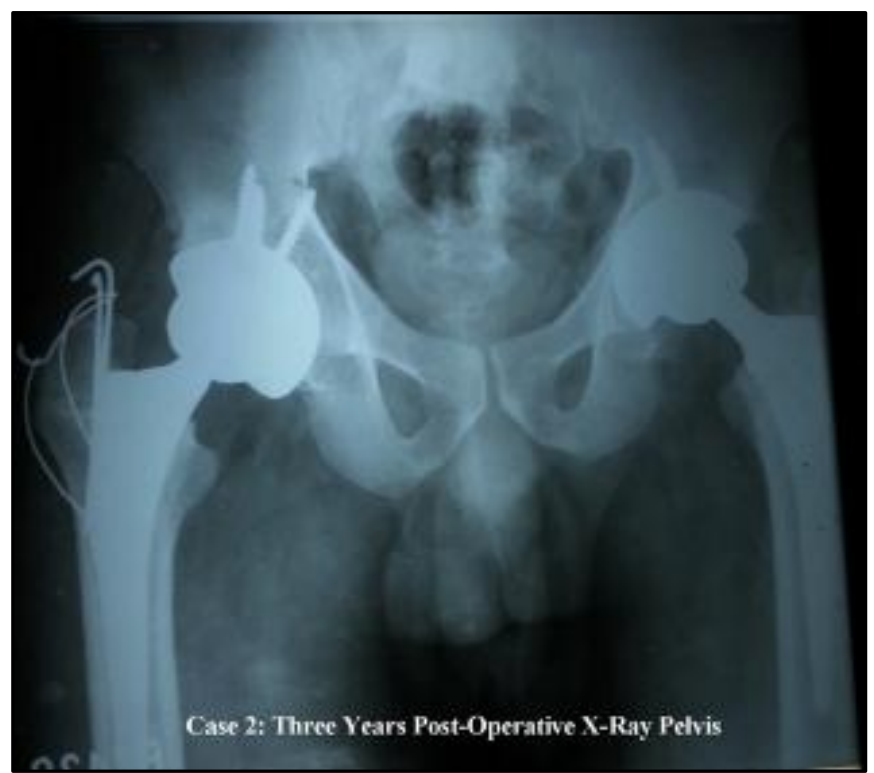

Case 2: Three Years Post-Operative X-Ray Pelvis

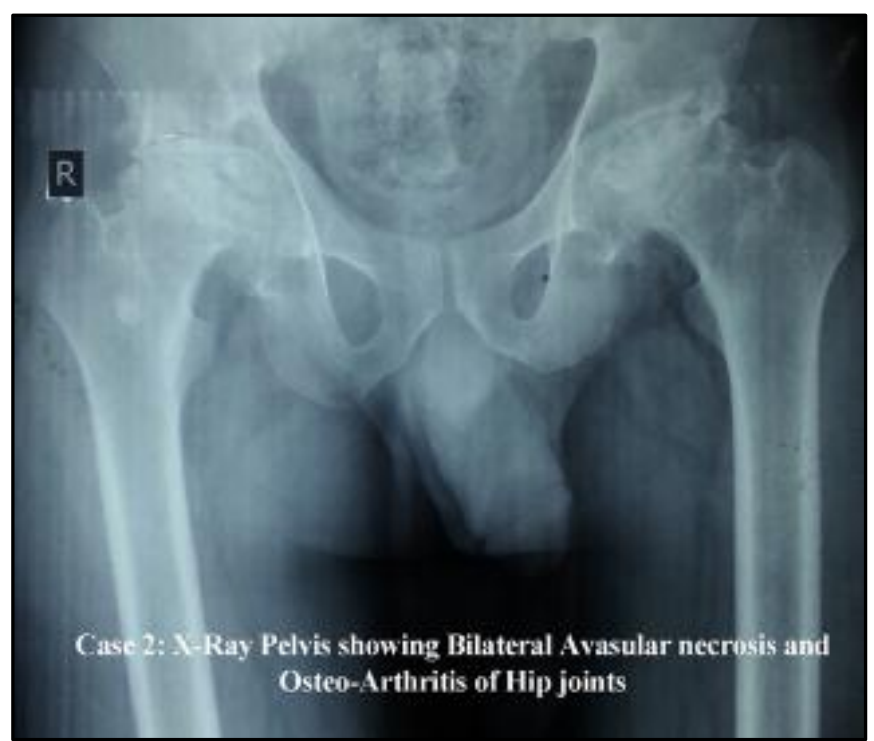

Case 2: X-Ray Pelvis showing Bilateral Avascular Necrosis and Osteoarthritis of HIP Joints

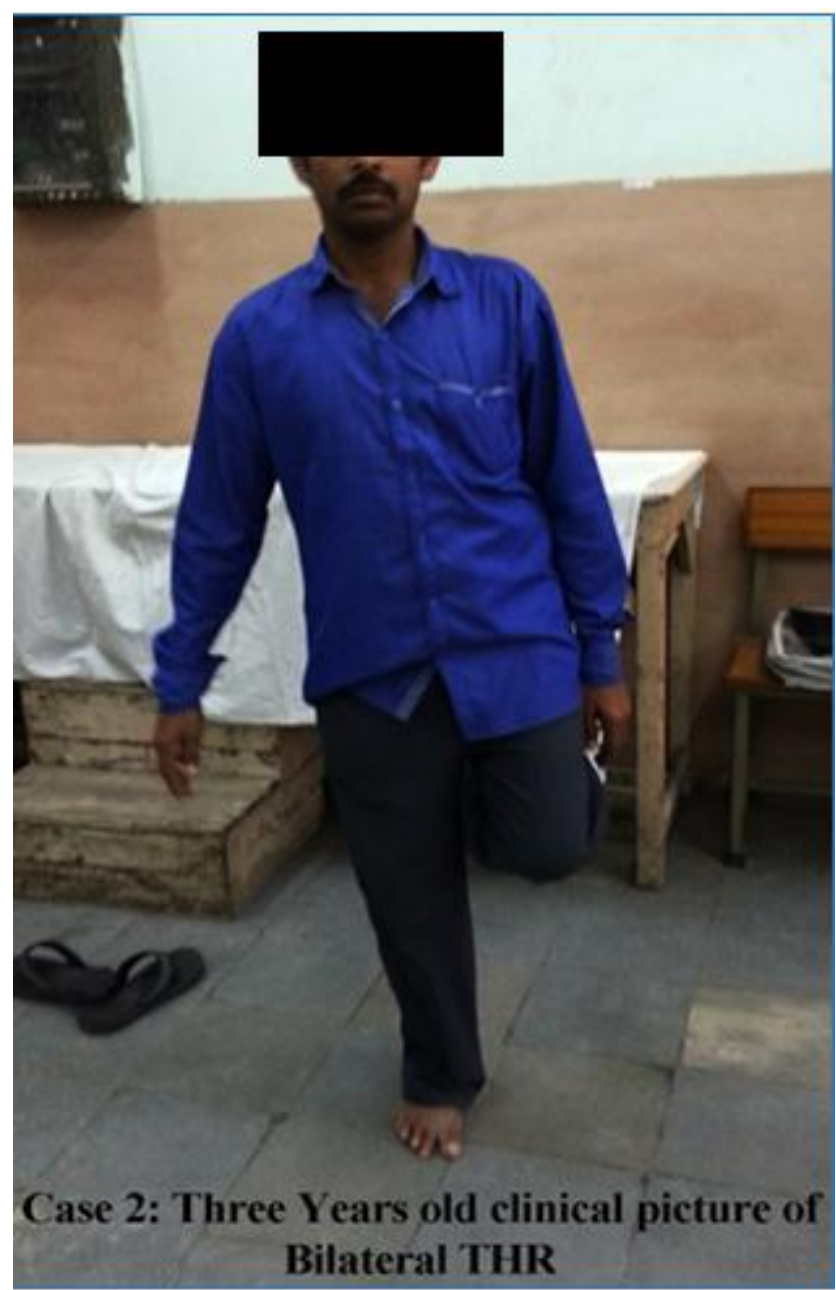

Case 2: Three Years Old Clinical Picture of Bilateral THR

\section{DISCUSSION}

Lot of research studies and publications have been done across the world comparing the cemented and uncemented THA and were of the opinion that Uncemented Total Hip Arthroplasty is one of the best procedures for the advanced Osteonecrosis of hip with arthritis. Eskelinen A.(11) et al. have published an article in the Finnish arthroplasty register. They have done 4,661 primary Total Hip Arthroplasty followed for 0-22 years in younger patients. The risk of stem revision due to aseptic loosening was higher in cemented stems than in proximally porous-coated (RR $5.5, \mathrm{p}<0.001$ ) or HA-coated (RR 6.6, $p=0.01$ ) uncemented stems. The risk of revision for all-polyethylene cemented cups was 3.0 times as high as that for press-fit porous-coated uncemented cups with aseptic loosening as endpoint $(\mathrm{p}=0.01)$.

Press-fit porous- and HA-coated uncemented cups may have better endurance against aseptic loosening than cemented cups in younger patients. Hungerford MW.(12) et al. examined the outcome of the femoral stem of four generations of an uncemented, proximally porous-coated, chrome-cobalt total hip prosthesis in 141 osteonecrosis patients, who had a mean age of 46 years. The mean followup was 103 months. Only of $8.9 \%$ had revision due to femoral stem loosening or osteolysis.

Proximally porous-coated, anatomic, press-fit stems provide excellent long-term results in patients with osteonecrosis of the femoral head. Mont MA.(13) et al. did a level III comparative study of uncemented total hip 
replacement in young patients between those suffering from osteonecrosis and from osteoarthritis. The outcome was good-to-excellent for $94 \%$ in the osteonecrosis group and $96 \%$ in the osteoarthritis group. Survivorship free of revision at the time of the latest follow-up was $96.1 \%$ for the osteonecrosis group and 98\% for the osteoarthritis group. Swedish Hip Arthroplasty Registry published by Hailer NP.(14) et al. have compared uncemented and cemented primary total hip arthroplasty.

Revision-free 10-year survival of uncemented THA was lower than that of cemented THA (85\% vs. 94\%, p<0.001), mainly related to poorer performance of uncemented cups. Uncemented stems perform better than cemented stems. Mark R. Brinker, MD, et al.(15) have studied ninety consecutive uncemented total hip arthroplasties in 73 young patients with osteonecrosis of the femoral head. Average Harris Hip Scores improved from 52.9 to 87.9 points. Total hip arthroplasty using non-cemented porous-coated femoral stems appears to give better results than cemented procedures in patients with osteonecrosis of the femoral head; the results appear to be inferior to those reported in patients with other diagnoses.

Epinette JA, Manley MT.(16) compared between HA coated versus plain porous femoral components. The literature has demonstrated better results with HA than porous alone both in terms of the quantity and quality of bone remodelling and the potential migration and subsidence of the stem. Dudkiewicz I.(17) et al. found that THA is a good option for the younger population even with Osteonecrosis, especially in bilateral disease. Aetiology did not affect the final outcome; however, patients with steroid-induced osteonecrosis should be informed that although their final functional results will equal those of other groups, the longevity of the implants is limited.

\section{CONCLUSION}

Uncemented Total Hip Arthroplasty (THA) is now generally regarded as the standard procedure for younger patients undergoing THA. For high-demand patients, modern THA bearings, such as ceramic-ceramic articulations and other improved Polyethylene and metal materials, provide high durability and low wear, if the components are properly aligned. Navigation technology has been introduced in THA to ensure perfect component positioning without outliers and concomitant risk of increased wear and implant failure. Minimally and less invasive approaches are becoming increasingly popular in order to facilitate rehabilitation and fast-track surgery in younger patients.

\section{REFERENCES}

1. Terry Canale S, Harold B Boyd, James H Beaty. Campbell's operative orthopaedics. part II, $13^{\text {th }}$ edition:pp 358.

2. Steinberg ME. Core decompression of the femoral head for avascular necrosis: indications and results. Can J Surg 1995;38(1):S18-24.

3. Shannon BD, Trousdale RT. Femoral osteotomies for avascular necrosis of the femoral head. Clin Orthop Relat Res 2004;418:34-40.
4. Gallinaro P, Massè A. Flexion osteotomy in the treatment of avascular necrosis of the hip. Clin Orthop Relat Res 2001;386:79-84.

5. Cabanela ME. The bipolar prosthesis in avascular necrosis of the femoral head. Semi Arthroplasty 1991;2(3):228-33.

6. Lee SB, Sugano N, Nakata K, et al. Comparison between bipolar hemiarthroplasty and THA for osteonecrosis of the femoral head. Clin Orthop Relat Res 2004;424:1615.

7. Lons A, Arnould A, Pommepuy T, et al. Excellent shortterm results of hip resurfacing in a selected population of young patients. Orthop Traumatol Surg Res 2015;101(6):661-5. doi: 10.1016/j.otsr.2015.07.011.

8. Marshall DA, Pykerman K, Werle J, et al. Hip resurfacing versus total hip arthroplasty: a systematic review comparing standardized outcomes. Clin Orthop Relat Res 2014;472(7):2217-30. doi: 10.1007/s11999-0143556-3.

9. Harris WH. Traumatic arthritis of the hip after dislocation and acetabular fractures: treatment by mold arthroplasty. An end result study using a new method of result evaluation. J Bone Joint Surg 1969;51-A:737-55.

10. Bellamy N, Campbell J, Stevens J, et al. Validation study of a computerized version of the western Ontario and McMaster universities VA 3.0 osteoarthritis index. J Rheumatol 1997;24:2413-2415.

11. Eskelinen A, Remes V, Helenius I, et al. Total hip arthroplasty for primary osteoarthrosis in younger patients in the Finnish arthroplasty register; 4,661 primary replacements followed for 0-22 years. Acta Orthop 2005;76(1):28-41.

12. Hungerford MW, Hungerford DS, Jones LC. Outcome of uncemented primary femoral stems for treatment of femoral head osteonecrosis. Orthop Clin North Am 2009;40(2):283-9. doi: 10.1016/j.ocl.2008.10.006.

13. Mont MA, Seyler TM, Plate JF, et al. Uncemented total hip arthroplasty in young adults with osteonecrosis of the femoral head: a comparative study. J Bone Joint Surg Am 2006;88(3):104-9.

14. Hailer NP, Garellick G, Kärrholm J. Uncemented and cemented primary total hip arthroplasty in the Swedish hip arthroplasty register. Acta Orthop 2010;81(1):3441. doi: 10.3109/17453671003685400.

15. Brinker MR, Rosenberg AG, Kull L, et al. Primary total hip replacement with non-cemented porus coated femoral stem in osteonecrosis of hip. Hip Int 2008;18(2):69-74.

16. Epinette JA, Manley MT. Uncemented stems in hip replacement--hydroxyapatite or plain porous: does it matter? Based on a prospective study of HA omnifit stems at 15 years minimum followup. Hip Int 2008;18(2):69-74.

17. Dudkiewicz I, Covo A, Salai M, et al. Total hip arthroplasty after avascular necrosis of the femoral head: does aetiology affect the results? Arch Orthop Trauma Surg 2004;124(2):82-5. 